\title{
Contrast Enhanced Digital Mammography
}

National Cancer Institute

\section{Source}

National Cancer Institute. Contrast Enhanced Digital Mammography. NCI Thesaurus.

Code C130042.

A digital mammography technique that incorporates the administration of an iodinated contrast agent to enhance lesions that are not visible on standard mammograms. 